\title{
Exploration of amplified fragment length polymorphism analysis as an effective tool for discriminating pathogenic strains of bacteria
}

This article was published in the following Dove Press journal:

Research and Reports in Forensic Medical Science

24 October 2012

Number of times this article has been viewed

K Weinbrecht ${ }^{1}$
A Taylor ${ }^{2}$
C Beaumann ${ }^{3}$
RW Allen'

'Department of Forensic Sciences, Center for Health Sciences,

Oklahoma State University, Tulsa, OK; ${ }^{2}$ Centers for Disease Control, Atlanta, GA; ${ }^{3}$ PharmaNet-i3, Indianapolis, IN, USA
Correspondence: Kate Weinbrecht Department of Forensic Sciences, IIII West 17th Street, Tulsa, OK 74107, USA

Tel +I $50370 \mid 3758$

Email kateldw@okstate.edu
Background: The detrimental effect pathogens used as bioweapons could have on the US is sufficient to warrant extensive efforts to establish preparedness to prevent, and, if necessary, respond to such an event. The objective of this research was to adapt and refine amplified fragment length polymorphism (AFLP) analysis for DNA profiling of microbial strains for use in forensic and clinical case work.

Methods: Included in this study were multiple strains of Pseudomonas syringae that were restricted in their respective host ranges (ie, the pathovars maculicola and tomato), Pseudomonas aeruginosa, Serratia marcescens, and Staphylococcus aureus. AFLP profiles were reduced to numeric haplotype codes that conveyed the size characteristics of the profiles.

Results: The AFLP assay exhibited over $97 \%$ reproducibility and every analyzed strain produced a unique haplotype code. Conserved areas of similarity were identified in haplotype codes of closely related strains of the same species, indicating that AFLP may also be a useful species identification tool, a possibility supported by cluster analysis of AFLP codes

Conclusion: The results of this study demonstrate that AFLP technology is sufficiently reproducible, powerful, and reliable for use as a broadly effective molecular screening tool in microbial forensics.

Keywords: amplified fragment length polymorphism, pathogenic strains, bacteria

\section{Introduction}

Several molecular techniques have been explored as investigators attempt to strengthen and focus efforts on developing effective and rapid techniques for microbial identification and attribution. ${ }^{1}$ Methods as general as multilocus sequence typing ${ }^{2,3}$ and variable number tandem repeat analysis ${ }^{4}$ have been applied to the differentiation of bacterial pathogens. Whole genome sequencing using high throughput technologies has also been utilized in the successful discrimination of bacteria..$^{5-7}$ Although sequencing will certainly discriminate bacteria at the species and strain level, there are other single nucleotide polymorphism detection methods that are also effective as discrimination tools. Amplified fragment length polymorphism (AFLP) analysis is one technique that analyzes single nucleotide polymorphisms within the genome. ${ }^{3}$ AFLP analysis has proven to be an effective research tool for discriminating DNA samples from a variety of bacterial species and strains. ${ }^{9-13}$ In this technique, genome-wide restriction analysis is performed to generate a collection of polymorphic restriction fragments which are then amplified and analyzed using capillary electrophoresis with fluorescent detection. ${ }^{8}$

Although AFLP analysis has been used as a research tool for the genetic fingerprinting of many microbial species, the reliability and suitability of this technique as a validated 
clinical and forensic tool is largely unknown and is a central theme of the study presented here. In this study, we assessed the AFLP method for reliability and discriminatory power by using the technique to analyze genomic DNA extracted from a diverse group of pathogenic bacteria. Included among the group were both Gram-negative and Gram-positive species. In some cases, strains of the same genus and species but differing at the pathovar level were also available for comparison.

Goals of this study beyond evaluating the utility of AFLP analysis as a routine clinical technique included assessing the discriminatory power of AFLP analysis by comparing closely related strains of a single species. In addition to establishing the discriminatory power of AFLP analysis, it was important to investigate the capacity of the assay to reveal conserved regions of the bacterial genome at the pathovar, species, and genus levels to ask whether or not the technique could be used to identify unknowns. Finally, a portable method capable of capturing the characteristics of an AFLP profile in an informative way was developed in the form of a numerical haplotype code. The production of a simple numerical code for each bacterial strain profile will allow laboratories to share information in a consistent and useful manner.

\section{Materials and methods}

\section{Bacterial strains}

All pathogenic bacteria were obtained from repositories maintained by members of the faculty of Oklahoma State University (see Table 1). Included among the pathogens tested were eight strains of $P$. syringae pathovar tomato, ten strains of Pseudomonas syringae pathovar maculicola, eight strains of Serratia marcescens, four strains of Pseudomonas aeruginosa, and seven strains of Staphylococcus aureus.

Each bacterial strain was cultured on Mueller-Hinton agar and incubated at $23^{\circ} \mathrm{C}$ (for $P$. syringae) or $37^{\circ} \mathrm{C}$ (for all others) until visual colonies formed. Once bacterial colonies were apparent, a $2 \mathrm{~mL}$ aliquot of Mueller-Hinton growth medium was inoculated with a single colony and incubated overnight with shaking. Each of the bacterial cultures was centrifuged at $10,000 \times \mathrm{g}$ for three minutes at room temperature to obtain a cell pellet for DNA extraction.

\section{DNA isolation}

Isolation of DNA from Gram-negative species began with resuspension of the cell pellet in $250 \mu \mathrm{L}$ of TNE $(10 \mathrm{mM}$ Tris- $\mathrm{Cl}, \mathrm{pH} 8.0,0.2 \mathrm{M} \mathrm{NaCl}$, and $1 \mathrm{mM}$ ethylenediamine tetra-acetic acid [EDTA]) with $15 \mathrm{mg} / \mathrm{mL}$ lysozyme, followed by incubation at $37^{\circ} \mathrm{C}$ for 30 minutes to weaken the cell walls. Once lysozyme digestion was complete, $250 \mu \mathrm{L}$ of TNE with $2 \%$ sodium dodecyl sulfate, $40 \mu \mathrm{L}$ proteinase $\mathrm{K}$ (20 mg/mL in $10 \mathrm{mM}$ Tris-Cl, pH 8.0, $0.2 \mathrm{M} \mathrm{KCl}$, and $50 \% \mathrm{v} / \mathrm{v}$ glycerol), and $2 \mathrm{mg}$ ribonuclease $\mathrm{A}$ was added to each sample. For Gram-positive bacteria (ie, S. aureus), the cell pellet was incubated with lysozyme as described above, but lysostaphin was also included in the mixture at $50 \mathrm{U} / \mathrm{mL}$ (Sigma Chemical Co, St Louis, MO).

All samples were allowed to incubate with sodium dodecyl sulfate and proteinase $\mathrm{K}$ at $65^{\circ} \mathrm{C}$ for one hour. Following incubation, the samples were extracted using an equal volume of phenol:chloroform/isoamyl alcohol (9:0.96:0.04 v/v). Samples were centrifuged at $10,000 \times \mathrm{g}$ for two minutes to induce phase separation. For each sample, the aqueous layer was then removed and placed in a clean $1.8 \mathrm{~mL}$ microfuge tube. The samples were extracted a second time with an equal volume of chloroform:isoamyl alcohol (24:1 v/v) and centrifuged at $10,000 \times \mathrm{g}$ for two minutes to obtain phase separation. The aqueous layer was removed to a clean $1.8 \mathrm{~mL}$ microfuge tube. Bacterial DNA was precipitated using two volumes of $95 \%$ ethanol. Using a sterile inoculation loop, the clot of DNA was retrieved from each sample and resuspended in $200 \mu \mathrm{L}$ of $\mathrm{TE}^{-4}$ (10 mM Tris-Cl, pH 8.0, 0.1 mM EDTA). The isolated

Table I Bacterial strains used in the study and their sources

\begin{tabular}{|c|c|c|}
\hline Species & Strains & Source \\
\hline Pseudomonas aeruginosa & $\begin{array}{l}\text { PAOI, I } 211 \text {, ATCC I0I45, } \\
\text { ATCC } 27853\end{array}$ & $\begin{array}{l}\text { Franklin R Champlin, Department of Biochemistry and Microbiology } \\
\text { Robert S Conrad, Department of Biochemistry and Microbiology } \\
\text { R Tom Glass, Department of Forensic Sciences }\end{array}$ \\
\hline $\begin{array}{l}\text { Pseudomonas syringae pathovar } \\
\text { maculicola }\end{array}$ & $\begin{array}{l}\text { FI5, FI8, F7, FIOA, FI2, NF3, } \\
\text { NF3A, NF5, NFI2, F22 }\end{array}$ & John Damicone, Department of Entomology and Plant Pathology \\
\hline $\begin{array}{l}\text { Pseudomonas syringae pathovar } \\
\text { tomato }\end{array}$ & $\begin{array}{l}\text { TI, CPST232, I88B, T4BI, } \\
\text { I } 318,1008, \text { CPSTI47, FF5 }\end{array}$ & Carol Bender, Department of Entomology and Plant Pathology \\
\hline Serratia marcescens & $\begin{array}{l}73 I \text { I7, HOIA, DBII, WOAI, } \\
\text { ZOAI, POAI, ROZ, ATCC }\end{array}$ & Jacqueline Fletcher, Department of Entomology and Plant Pathology \\
\hline Staphylococcus aureus & $\begin{array}{l}\text { SA0003, 9D9, MID7, 292b, } \\
4 \mathrm{i} 2, \mathrm{SA} 0002, \mathrm{SA} 000 \mathrm{I}\end{array}$ & R Tom Glass, Department of Forensic Sciences \\
\hline
\end{tabular}


DNA samples were quantitated spectrophotometrically at $260 \mathrm{~nm}$ and $280 \mathrm{~nm}$ using a Nanodrop ND-1000 microspectrophotometer (Thermo Scientific, Wilmington, DE) and then stored at $4^{\circ} \mathrm{C}$, if not immediately used.

\section{DNA digestion}

Aliquots of $500 \mathrm{ng}$ of DNA extracted from the different bacterial strains were digested sequentially with a 5-10-fold excess of EcoR 1 and Msel (both obtained from New England Biolabs Inc, Beverly, MA) following the manufacturer's instructions. To determine the completeness of digestion, an aliquot of each digest was electrophoresed on $1 \%$ agarose gel equilibrated in TAE buffer $(10 \mathrm{mM}$ Tris-acetate $\mathrm{pH} 8.3$ with $1 \mathrm{mM}$ EDTA). The distribution of restriction fragments in each gel track was visualized using ethidium bromide staining and ultraviolet illumination. Successful DNA digestion was indicated by a smear of restriction fragments in the gel track, and a lack of a discernible, discreet high molecular weight band near the sample well. Once digestion was confirmed, $6 \mu \mathrm{L}$ of $\mathrm{TE}^{-4}$ was added to $4 \mu \mathrm{L}$ of digested DNA. If not used immediately, the DNA samples were stored at $4{ }^{\circ} \mathrm{C}$.

\section{DNA ligation}

Oligonucleotide adaptor pairs provided with the microbial AFLP genotyping kit (Applied Biosystems Inc, Foster City, CA) were ligated onto the ends of the restriction fragments following instructions provided by the manufacturer. Incubation for DNA ligation was carried out in a thermocycler holding a constant $37^{\circ} \mathrm{C}$ temperature. Each adaptor pair harbors a sequence complementary to the sticky ends of either the Msel and EcoRl fragments produced during restriction digestion, and adaptors also have additional sequence that will serve as annealing target sites for the polymerase chain reaction (PCR) primers used in both the preselective and selective PCR steps. After ligation was complete, $189 \mu \mathrm{L} \mathrm{TE}^{-4}$ was added to each sample. The concentration of ligated restriction fragments in the diluted sample was calculated to be approximately $100 \mathrm{pg} / \mathrm{uL}$. If not immediately used, the samples were stored at $4^{\circ} \mathrm{C}$.

\section{Preselective amplification}

The first of two rounds of PCR in the AFLP technique is preselective amplification of all ligated restriction fragments produced during the prior steps in the process. ${ }^{8}$ Two primers are utilized, ie, an EcoR1 preselective primer (Applied Biosystems Inc) targeting the DNA fragment ends created by ligation of the EcoRI adapter, and an Msel preselective primer (Applied Biosystems Inc) targeting the DNA fragment ends created by ligation of the Msel adapter. Neither of the preselective primers are labeled with fluorescent dyes. Approximately $100 \mathrm{pg}$ of ligated DNA (calculated considering dilution from the original DNA) was amplified following instructions provided by the manufacturer.

Successful DNA ligation and preselective amplification were assessed by electrophoresis of an aliquot of preselective amplicons in 1\% agarose gel equilibrated in TAE buffer. If the ligation and non-selective amplification steps were successful, a smear of PCR products was visible in the gel track when stained with ethidium bromide and viewed under ultraviolet light. It should be noted that if either ligation or preselective amplification failed, the agarose gel track would show no evidence of ethidium bromide staining.

\section{Selective amplification}

Selective amplification is the second of the two rounds of PCR in the AFLP method. ${ }^{8}$ Selective amplification reduces the final number of DNA fragments that will be analyzed by utilizing a set of primers that target a subset of nonselectively amplified products containing an EcoR1 site on one end of the fragment and an Mse1 site on the other. In addition to targeting the sequences of the EcoR1 and Mse1 linkers ligated to restriction fragments, selective primers also contained an additional nucleotide at the $3^{\prime}$ end that extends one nucleotide into the sequence of the genomic restriction fragment. Thus, restriction fragments successfully amplified by selective PCR must not only contain EcoR1 and Mse1 linkers, but must also contain a nucleotide in the genomic sequence that is complementary to the one base extension in the selective primer. The requirement for the additional one base complementarity between the selective primers and the target restriction fragment reduces the number of genomic restriction fragments that will ultimately constitute the AFLP profile from the sample. ${ }^{13}$ In addition, the selective primer targeting the EcoRl end of nonselective PCR products is labeled with one of three fluorescent dyes, depending on the selective nucleotide coupled to each primer. The $M s e 1$ primer used for selective amplification is unlabeled but has an extra adenosine nucleotide at the $3^{\prime}$ end of the primer, therefore only amplifying fragments that have the Msel target sequence followed directly by a thymidine nucleotide in the genomic DNA sequence (Applied Biosystems Inc). Three different selective EcoRl primers were used for amplification, each with a different nucleotide extension, ie, adenosine, guanine, or cytosine. The $E c o R 1$ primers were coupled with a different fluorescent dye, EcoRl-A with FAM (blue), EcoRl-G with JOE (green), and EcoRl-C with NED (yellow). Every sample was amplified with the Msel-A primer plus one of 
the selective EcoR 1 primers. Three different selective PCR reactions were thus created for each DNA sample following the instructions provided by the manufacturer. Each of the three reactions for each strain was prepared in a separate microcentrifuge tube, yielding three separate amplified products for each individual strain. Reactions containing each of the three possible primer pairs, each tagged with a different fluorescent dye, were amplified and electrophoresed separately by capillary electrophoresis in order to avoid pullup problems between color channels.

\section{Capillary electrophoresis}

Capillary electrophoresis was performed using an ABI Prism 310 genetic analyzer (Applied Biosystems Inc). Samples were electroinjected into the capillary for 5 seconds and electrophoresed for 24 minutes at $60^{\circ} \mathrm{C}$. Three electropherograms were produced for each sample, one for amplicons labeled with FAM (blue), one for amplicons labeled with JOE (green), and one for amplicons labeled with NED (yellow, appearing as black), as shown in Figure 1.

\section{Analysis}

AFLP data analysis was performed initially using Genemapper ID software (version 3.2) to categorize each AFLP product by size and relative fluorescence. Once AFLP profiles were produced for a strain, the electropherogram of fluorescent PCR products was converted into a numerical haplotype code. The numerical haplotype code assigned to each strain conveyed the distribution of labeled amplicons, within a size range of 75-350 base pairs for amplicons produced using each of the three selective primers. This size range was chosen somewhat arbitrarily, but resolution of DNA fragments is maximal in the chosen range on the capillary electrophoresis platform used. The resulting 275 base pairs of size range was subdivided into $27 \times 10$ base pair size bins plus $1 \times 5$ base pair bin (from $345-350$ base pairs). The haplotype code thus consists of either a zero (for size bins lacking amplicons) or a number corresponding to the number of distinct amplicons, the size of which places them in a particular bin (normally a number ranging from 1 to 3 ).

The analytical threshold for scoring AFLP amplicons was established as a relative value for each AFLP run by determining the average relative fluorescence units for all amplicons within the 75-350 base pair size range and then dividing that average by 2 . This approach, rather than a static threshold, allowed different AFLP electropherograms to be "normalized" to one another and greatly enhanced reproducibility. Only amplicon products that exceeded the analytical threshold were scored as part of the AFLP profile and thus included in the haplotype code. Final haplotype codes assigned to each bacterial strain consisted of three parts representing the code for each electropherogram labeled with FAM, JOE, or NED.

\section{Results}

\section{Reproducibility}

To investigate AFLP reproducibility, analysis was performed in triplicate for 10 strains of $P$. syringae pathovar maculicola and four strains of $P$. aeruginosa. Reproducibility was quantified based on the location of peaks (representing DNA restriction fragment size) observed in the electropherograms for each strain. Reproducibility among the triplicate electropherograms can be assessed by visual inspection of peak location and size estimation. For example, the three NED electropherograms for $P$. syringae pathovar maculicola

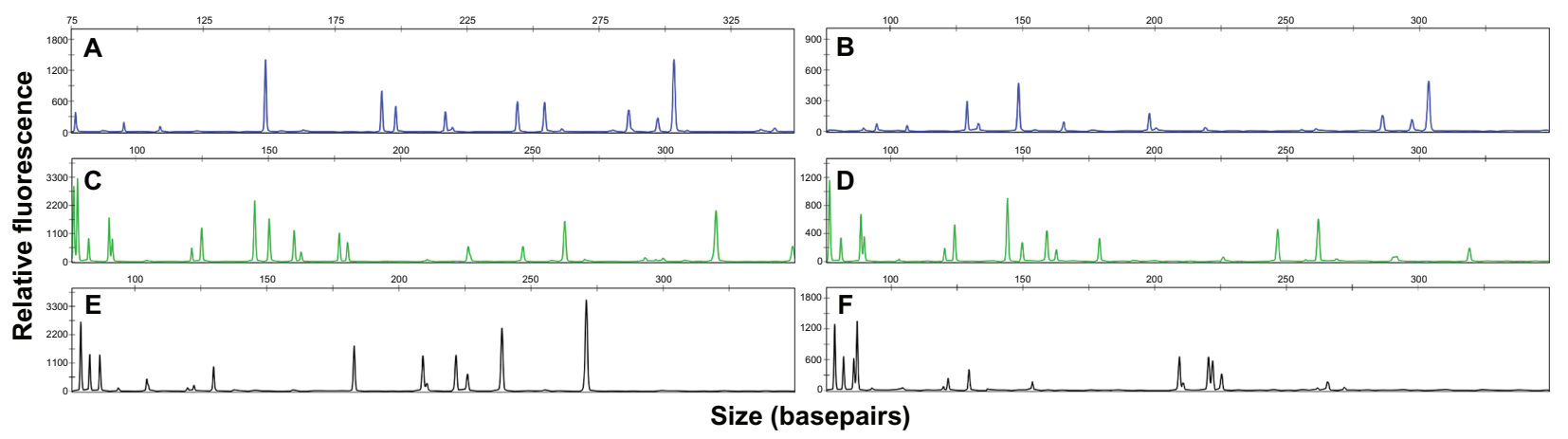

Figure I AFLP analysis of two strains of Pseudomonas syringae pathovar maculicola. DNA from strains FIOA (panels A, C, and E) and F7 (panels B, D, and F) was used to produce the AFLP profiles.

Notes: The abscissa in each panel is fragment size (in base pairs) and the ordinate is shown as relative fluorescence units. Each fluorescent peak in the histogram represents an amplified restriction fragment produced by initial digestion of the genomic DNA with Eco RI and Mse I restriction endonucleases.

Abbreviation: AFLP, amplified fragment length polymorphism. 
strain NF12 appear consistent with one another when peak location is visually compared (Figure $2 \mathrm{~A}-\mathrm{C}$ ). Although the relative fluorescence of the peaks does change in each individual run, the AFLP profiles for this strain are consistent throughout each of the three electropherograms for each selective primer used.

Reproducibility was also assessed by comparing the haplotype codes produced for each replicate electropherogram generated for strains of $P$. syringae pathovar maculicola and pathovar tomato as well as $P$. aeruginosa. When calculating percent reproducibility, the following formula was used:

(Number of matching bins $\div$ Total number of bins) $\times 100=\%$ of reproducibility

The total number of bins was always 84 , because there are 28 bins possible in the haplotype code for each color channel (FAM, JOE, and NED). The number of matching bins was calculated as the proportion of the total observed for whichever run (among the triplicates) exhibited the greatest number of scored AFLP amplicons. Differences in peak number among the replicates were due to lower relative fluorescence unit amplicons that sometimes did not achieve the analytical threshold and thus were not scored. The reproducibility was first determined for each bacterial strain within each color channel (among the triplicate analyses). Reproducibility calculations were then extended to include all of the strains within a given species. The lowest reproducibility value calculated for a single strain was $95.6 \%$ for P. syringae strain F7. The highest reproducibility value calculated for a single strain was $100.0 \%$ for $P$. syringae strain F22. The overall reproducibility for $P$. syringae pathovar maculicola was $97.9 \%$ and the overall reproducibility for $P$. aeruginosa was $97.5 \%$.

\section{Discriminatory capability}

AFLP analysis is known to have a high degree of discriminatory power when used to analyze DNA from a variety of species. ${ }^{8}$ In this study, AFLP analysis was used to characterize bacteria representing pathogenic species that target plants and humans. Among the plant pathogens, different pathovars of the same species and different strains within

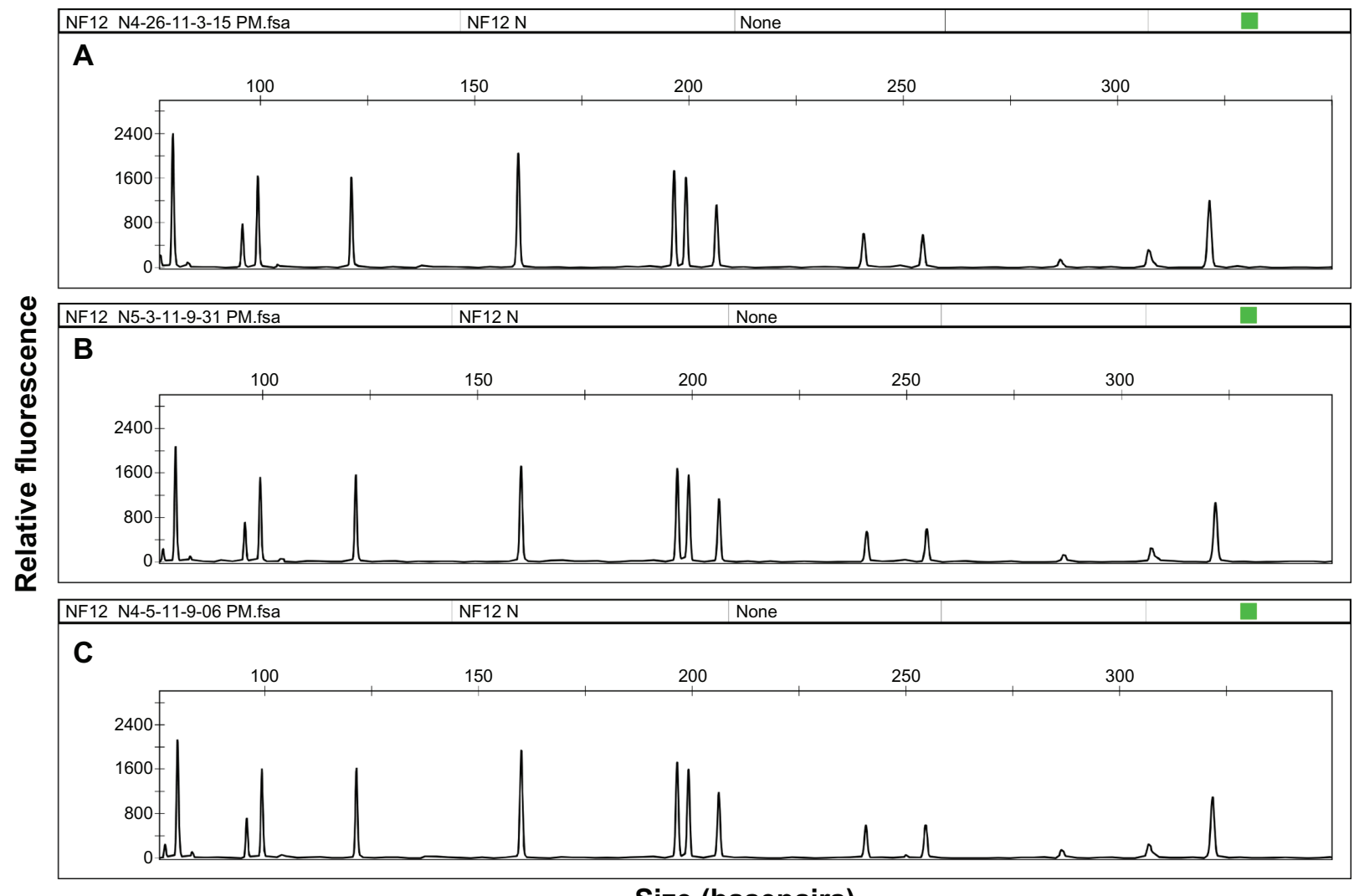

\section{Size (basepairs)}

Figure 2 AFLP profiles produced from triplicate analysis of Pseudomonas syringae strain NFI2 (NED-labeled profiles shown only).

Notes: AFLP profiles were produced in triplicate from strain NFI 2 P. syringae bacteria. Although AFLP profiles were produced for each Eco RI primer, only the profile for the NED-labeled selective primer is shown. Abscissa of each panel reflects the size in base pairs of each fragment while the ordinate of each panel reflects relative fluorescence. Abbreviation: AFLP, amplified fragment length polymorphism. 
a pathovar, in some cases isolated from different infected plants in the same field, were subjected to AFLP analysis to assess the ability of the assay to discriminate closely related strains. All 37 bacterial strains analyzed in this study generated distinct electropherograms and distinct haplotype codes (not shown). The electropherograms for each bacterial strain could be distinguished visually from one another. Although two closely related strains share a large number of conserved amplicon products in their respective electropherograms visually, clear differences in the FAM, JOE, and/or NED electropherograms never failed to distinguish each strain from the others (Figure 1A-F).

The creation of a haplotype code for each bacterial strain facilitated data capture and comparison for AFLP profiles from the bacterial strains. At the same time, haplotype codes retained the ability to convey even subtle differences in electropherograms. Thus, the haplotype code also retained the discriminatory power inherent in AFLP analysis. Reviewing the haplotype codes for $P$. syringae strains F7 and F10A, it is apparent that the two strains share many of the same profile characteristics, consistent with belonging to the same species and pathovar groups, yet differences exist allowing the strains to be distinguished (Table 2).

\section{Genetic relatedness}

In addition to the discriminatory power of AFLP we were interested in the ability of the coding technique to capture similarities amongst the bacterial strains. This is important because of the potential for AFLP analysis to be useful for identification of an unknown bacterium based upon benchmark characteristics that are conserved within the genome of a particular species, or perhaps even pathovar. Agglomerative hierarchical clustering (XLSTAT, Addinsoft Inc, Brooklyn, NY) was used to analyze haplotype codes, looking for conserved elements in the code that could be used to group the different strains based upon relatedness. Agglomerative hierarchical clustering places data (in this case strain haplotype codes) together in a group based on similarity revealed through a stepwise comparison process and ultimately displays that similarity in the form of a dendrogram. Agglomerative hierarchical clustering analysis of AFLP haplotype codes produced the dendrogram shown in Figure 3. The order in which the strains are listed in the dendrogram reflects haplotype code similarity (and thus genetic similarity) among the analyzed strains. For example, it is evident that the P. syringae pathovar maculicola strains show a closer genetic relationship with the $P$. syringae pathovar tomato strains than to strains of $P$. aeruginosa, $S$. marcescens, or $S$. aureus. The
P. syringae pathovar maculicola strains also have a fairly close relationship with the $P$. aeruginosa strains, which fall into a separate group (Figure 3). The S. marcescens and $S$. aureus strains appear to be the least genetically similar to the $P$. syringae pathovar maculicola strains because they appear in a group located the greatest distance from P. syringae in the dendrogram (Figure 3 ).

\section{Discussion}

In order for an assay to be useful in a clinical or forensic testing capacity, it must be validated. In this context, validation incorporates a deep understanding of the performance characteristics of the assay with emphasis on precision and reproducibility. An effective microbial DNA typing technique must be reproducible, highly discriminatory, and ideally produce portable results that can be easily shared among laboratories. In this study, the essential elements of precision and reproducibility were investigated for the AFLP technique when used to discriminate several species of pathogenic bacteria. Similar results using AFLP analysis have been reported by others analyzing a variety of prokaryotic and eukaryotic organisms, representing plant, animal, and human pathogens. ${ }^{9,11,14,15}$ However, those reports were primarily descriptive and did not involve a detailed analysis of reproducibility nor was the AFLP profile produced captured in a portable way. The results of this study suggest that AFLP analysis can be performed reliably and can effectively differentiate between bacteria at the pathovar, strain, and species level, and that the essential elements of an AFLP profile can be captured in a simplistic haplotype code that can be readily shared among laboratories.

Reliability as reflected in reproducibility is critical for a useful DNA typing tool. In that regard, performance of the AFLP assay with multiple strains of $P$. syringae pathovar maculicola and several strains of $P$. aeruginosa, in which detailed analysis was performed, revealed the assay to have an overall reproducibility of $97.9 \%$ for $P$. syringae pathovar maculicola strains and an overall reproducibility of $97.5 \%$ for $P$. aeruginosa. A successful molecular typing tool must also have a high discriminatory power in order to differentiate between closely related strains and species. In this study, the AFLP assay demonstrated a high degree of discriminatory power with all 37 strains of bacteria, encompassing two closely related pathovars and four different species.

Although a high discriminatory power is important for an effective DNA typing assay, the similarities in haplotype codes among strains of the same species can also aid in identification of an unknown microbe. Agglomerative hierarchical 


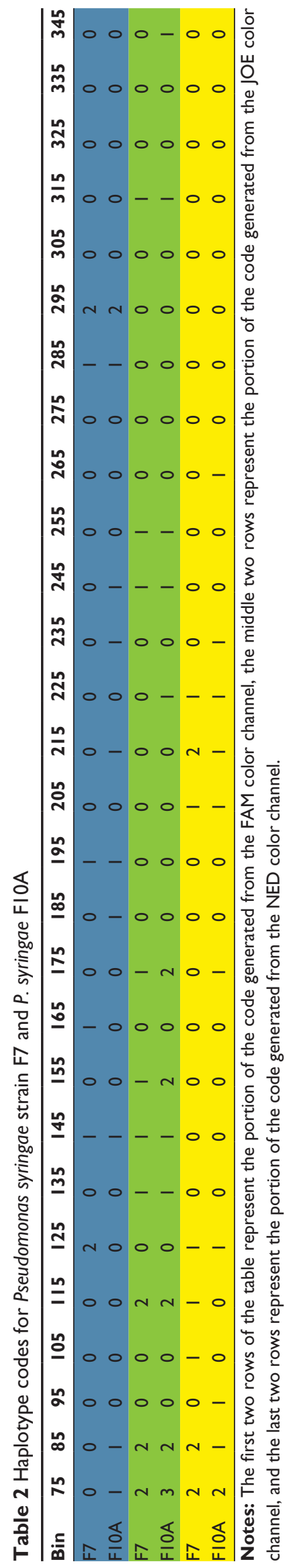

clustering established that in addition to each strain being uniquely identifiable based on its haplotype code, strains of the same species also share conserved stretches in their codes. It should be noted that the results of the agglomerative hierarchical clustering analysis are consistent with species and strain descriptions provided by their sources.

The results of AFLP analysis demonstrated genetic relationships that would be expected for strains of the same pathovar or species. For example, agglomerative hierarchical clustering grouped pathovars of $P$. syringae (which included pathovar tomato and pathovar maculicola) into the expected clusters and placed the species next to one another within the dendogram (Figure 3). The results shown in the dendogram also highlight the potential for AFLP analysis to be useful for strain identification inasmuch as those "benchmark" characteristics of the AFLP profiles are conserved and reflected in the haplotype codes at the species and possibly pathovar levels. Therefore, it might be possible for AFLP analysis to place an unknown microbe within a particular characterized group.

The characteristics of optimized AFLP analysis make the assay useful for a number of clinical applications. Current methods for genetically comparing food-borne pathogens in health department laboratories involve restriction analysis of genomic DNA followed by agarose gel electrophoresis using pulsed field gel electrophoresis. ${ }^{16}$ The field of human identity testing evolved from agarose gel-based separation of DNA restriction fragments to the use of capillary electrophoresis platforms and this move greatly enhanced the resolution of the separation technique. Thus, in this regard, AFLP analysis could represent technological advance in the public health area inasmuch as the technology described here utilizes capillary electrophoresis and thus maximizes resolution which, in our opinion, contributes to the overall reproducibility of the assay.

AFLP analysis is also a candidate methodology for investigation of biocrimes involving pathogenic bacteria. The potential for terrorist acts to target the agricultural industry makes including plant pathogens in any study of DNA analysis technologies a logical choice. AFLP is a good candidate technology to be used in the identification, differentiation, and attribution of a microbial strain in the event of a biocrime. The work presented here includes the analysis of a wide variety of bacterial species used to represent the diversity of microbial pathogens that one might be able to access for use as a biological weapon. The goal of the study was thus to assess the utility of AFLP as a "universal" DNA typing method applicable to a wide variety of bacterial species. 


\section{Genetic relatedness dendrogram}

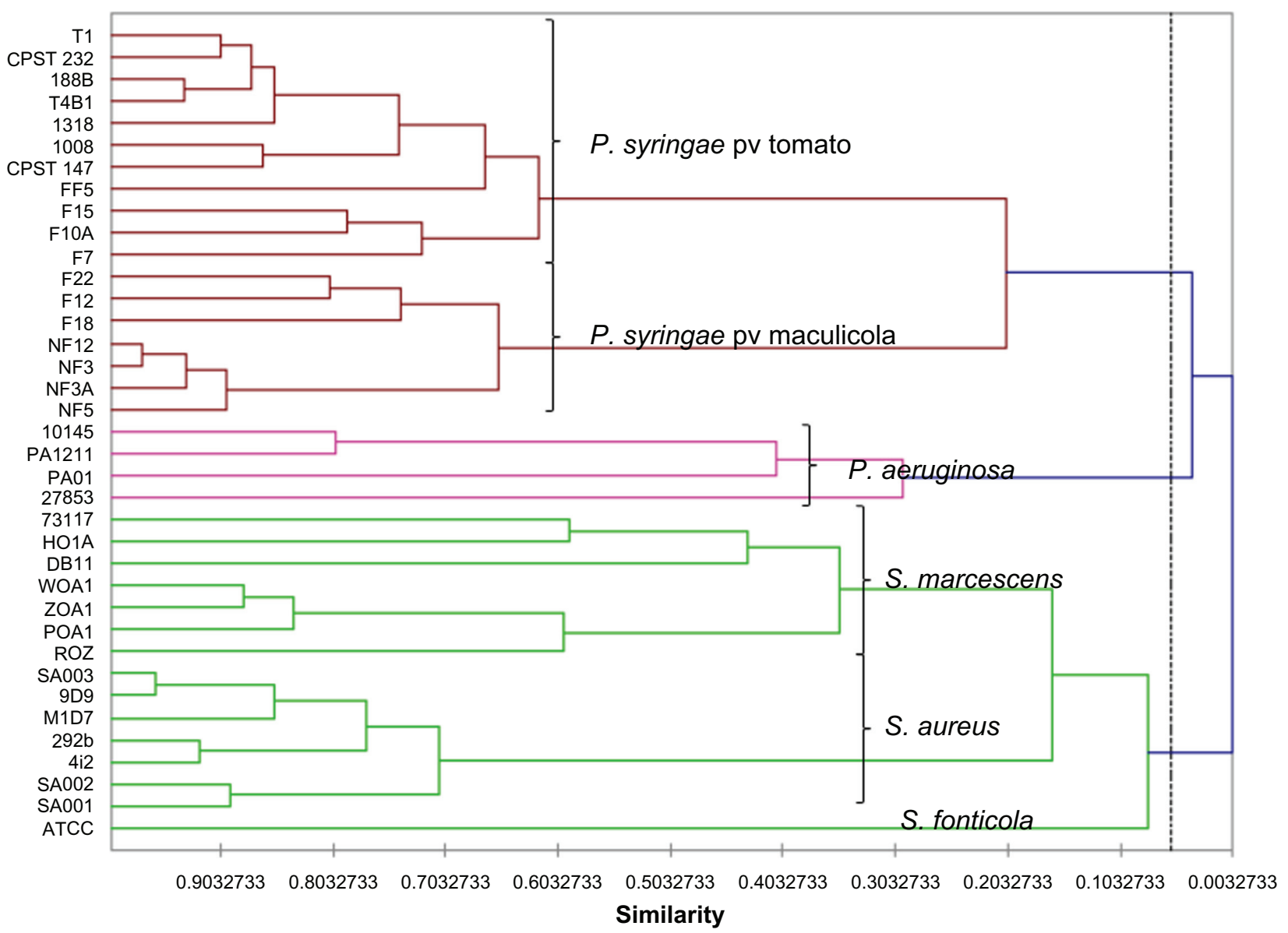

Figure 3 Agglomerative hierarchical cluster analysis of AFLP haplotype codes. Haplotype codes were produced for each of the different bacterial strains subjected to AFLP analysis. Excel spreadsheets containing the codes were imported into XLSTAT software (http://www.xlstat.com) and agglomerative hierarchical clustering was performed, producing the dendogram. Strains are clustered in the dendogram according to the relatedness of the codes.

Abbreviation: AFLP, amplified fragment length polymorphism.

The AFLP analysis technique can be performed routinely in 2-3 days and the method is also compatible with analyzing multiple strains simultaneously in a semiautomated way. Thus, the technique could be readily implemented in high-throughput laboratories working primarily in the public health and defense sectors.

\section{Acknowledgment}

This research was supported in part by funds from the HA and Mary K Chapman Charitable Trust and by a grant from the US Department of Agriculture.

\section{Disclosure}

The authors report no conflicts of interest in this work.

\section{References}

1. Cummings CA, Relman DA. Genomics and microbiology: microbial forensic - "cross-examining pathogens". Science. 2002;296(5575): 1976-1979.
2. Maiden MC, Bygraves JA, Feil E, et al. Multilocus sequence typing: a portable approach to the identification of clones within populations of pathogenic microorganisms. Proc Natl Acad Sci U SA. 1998;95(6): 3140-1345.

3. Maiden MC. Multilocus sequence typing of bacteria. Annu Rev Microbiol. 2006;60:561-588.

4. Whatmore AM, Shankster SJ, Perrett TJ, et al. Identification and characterization of variable number tandem-repeat markers for typing of Brucella spp. J Clin Microbiol. 2006;44(6):1982-1993.

5. Cummings CA, Bormann Chung CA, Fang R, et al. Accurate, rapid, and high-throughput detection of strain-specific polymorphisms in Bacillus anthracis and Yersinia pestis by next-generation sequencing. Investig Genet. 2010;1(5):1-14.

6. Read TD, Salzberk SL, Pop M, et al. Comparative genome sequencing for discovery of novel polymorphisms in Bacillus anthracis. Science. 2002;296(5575):2028-2033.

7. Enserink M. Anthrax investigation. Full genome sequencing paved the way from spores to a suspect. Science. 2008;321(5891):898-899.

8. Clerc C, Manceau C, Nesme X. Comparison of randomly amplified polymorphic DNA with amplified fragment length polymorphism to assess the genetic diversity and genetic relatedness with genospecies III of Pseudomonas syringae. Appl Environ Microbiol. 1998;64(4):1180-1187.

9. Geornaras I, Kenene NF, von Holy A, Hastings JW. Amplified fragment length polymorphism fingerprinting of Pseudomonas strains from a poultry processing plant. Appl Environ Microbiol. 1999;5(9): $3828-3833$. 
10. Jackson PJ, Hill KK, Laker MT, Ticknor LO, Keim P. Genetic comparison of Bacillus anthracis and its close relatives using amplified fragment length polymorphism and polymerase chain reaction analysis. J Appl Microbiol. 1999;87(2):263-269.

11. Janssen P, Coopman R, Huys G, et al. Evaluation of the DNA fingerprinting method AFLP as a new tool in bacterial taxonomy. Microbiology. 1996;142(Pt 7):1881-1893.

12. Lin J, Kuo J, Ma J. A PCR-based DNA fingerprinting technique: AFLP for molecular typing of bacteria. Nucleic Acids Res. 1996;4(18): 3649-3650.

13. Vos P, Hogers R, Bleeker M, et al. AFLP: a new technique for DNA fingerprinting. Nucleic Acids Res. 1995;23(21):4407-4414.
14. Datwyler SL, Weibllen GD. Genetic variation in hemp and marijuana Cannabis sativa L. according to amplified fragment length polymorphisms. J Forensic Sci. 2006;51(2):371-375.

15. Hill KK, Lawrence OT, Okinaka RT, et al. Fluorescent amplified fragment length polymorphism analysis of Bacillus anthracis, Bacillus cereus, and Bacillus thuringiensis isolates. Appl Environ Microbiol. 2004;70(2):1068-1080.

16. Ribot EM, Fair MA, Gautom R, et al. Standardization of pulsed-field gel electrophoresis protocols for the subtyping of Escherichia coli O157:H7, Salmonella, and Shigella for pulseNet. Foodborne Pathog Dis. 2006;3(1):59-67.

\section{Publish your work in this journal}

Research and Reports in Forensic Medical Science is an international, peer-reviewed, open access journal publishing original research, reports, reviews and commentaries on all areas of forensic medical science. The manuscript management system is completely online and includes a very quick and fair peer-review system. Visit http://www.dovepress.com/ testimonials.php to read real quotes from published authors. 